\title{
Optical extinction by upper tropospheric/stratospheric aerosols and clouds: GOMOS observations for the period 2002-2008
}

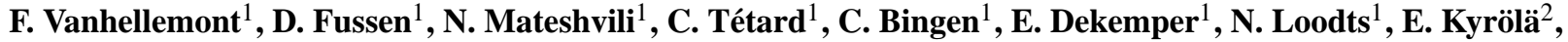 \\ V. Sofieva ${ }^{2}$, J. Tamminen ${ }^{2}$, A. Hauchecorne ${ }^{3}$, J.-L. Bertaux ${ }^{3}$, F. Dalaudier ${ }^{3}$, L. Blanot ${ }^{3,4}$, O. Fanton d'Andon ${ }^{4}$, \\ G. Barrot $^{4}$, M. Guirlet ${ }^{4}$, T. Fehr ${ }^{5}$, and L. Saavedra ${ }^{5}$ \\ ${ }^{1}$ Belgian Institute for Space Aeronomy, Brussels, Belgium \\ ${ }^{2}$ Finnish Meteorological Institute, Helsinki, Finland \\ ${ }^{3}$ Service d'Aéronomie du CNRS, Verrieres-le-Buisson, France \\ ${ }^{4}$ ACRI-ST, Sophia-Antipolis, France \\ ${ }^{5}$ ESA-ESRIN, Frascati, Italy
}

Received: 2 February 2010 - Published in Atmos. Chem. Phys. Discuss.: 26 April 2010

Revised: 18 August 2010 - Accepted: 24 August 2010 - Published: 27 August 2010

\begin{abstract}
Although the retrieval of aerosol extinction coefficients from satellite remote measurements is notoriously difficult (in comparison with gaseous species) due to the lack of typical spectral signatures, important information can be obtained. In this paper we present an overview of the current operational nighttime UV/Vis aerosol extinction profile results for the GOMOS star occultation instrument, spanning the period from August 2002 to May 2008. Some problems still remain, such as the ones associated with incomplete scintillation correction and the aerosol spectral law implementation, but good quality extinction values are obtained at a wavelength of $500 \mathrm{~nm}$. Typical phenomena associated with atmospheric particulate matter in the Upper Troposphere/Lower Stratosphere (UTLS) are easily identified: Polar Stratospheric Clouds, tropical subvisual cirrus clouds, background stratospheric aerosols, and post-eruption volcanic aerosols (with their subsequent dispersion around the globe). For the first time, we show comparisons of GOMOS $500 \mathrm{~nm}$ particle extinction profiles with the ones of other satellite occultation instruments (SAGE II, SAGE III and POAM III), of which the good agreement lends credibility to the GOMOS data set. Yearly zonal statistics are presented for the entire period considered. Time series furthermore convincingly show an important new finding: the sensitivity of GOMOS to the sulfate input by moderate volcanic eruptions such as Manam (2005) and Soufrière Hills (2006). Finally, PSCs are well observed by GOMOS and a first qual-
\end{abstract}

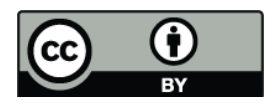

Correspondence to: F. Vanhellemont (filip.vanhellemont@aeronomie.be) itative analysis of the data agrees well with the theoretical PSC formation temperature. Therefore, the importance of the GOMOS aerosol/cloud extinction profile data set is clear: a long-term data record of PSCs, subvisual cirrus, and background and volcanic aerosols in the UTLS region, consisting of hundreds of thousands of altitude profiles with near-global coverage, with the potential to fill the aerosol/cloud extinction data gap left behind after the discontinuation of occultation instruments such as SAGE II, SAGE III and POAM III.

\section{Introduction}

Upper tropospheric and stratospheric particles (whether liquid or solid) are intensively studied for a number of reasons that can be roughly summarized as follows: (1) they have an impact on the Earth radiative balance due to their optical properties, (2) they play a crucial role in heterogeneous chemistry, and (3) they provide information on the emission of precursor species from which they originate. Here, the word 'particles' should be taken in its most general context: liquid or solid aerosols of submicron size, cloud droplets or crystals with sizes of tens or hundreds of microns, etc. From previous experiences with satellite occultation instruments, we know that a few particle types are commonly encountered in the measurements: stratospheric aerosols, tropical subvisual cirrus clouds and Polar Stratospheric Clouds (PSCs).

The stratospheric aerosol layer (or Junge layer, named after its discoverer; see Junge et al., 1961) consists of liquid droplets composed of a mixture of sulphuric acid and water. The layer manifests itself in a pronounced way after

Published by Copernicus Publications on behalf of the European Geosciences Union. 
major volcanic eruptions that are powerful enough to inject teragrams of $\mathrm{SO}_{2}$ into the stratosphere, such as the ones of Mount Pinatubo (the Philippines, 1991) or El Chichón (Mexico, 1982); see Robock (2000). After an oxidation process, sulfate aerosols are formed that are subsequently transported globally, depending on the latitude of the eruption. Eventually they are removed from the stratosphere, although this process can take years. Nevertheless, the last major eruption (Mount Pinatubo) dates already from 18 years ago, and the stratospheric aerosol layer returned to its "background" level around 1997. Since then, no significant trend is observed in data from SAGE II, balloon-borne instruments and lidars (Deshler et al., 2003, 2006), even when compared with volcanically quiet years such as 1979 . These findings suggest a more or less stable input of sulphuric species in the stratosphere that maintain the background layer. Crutzen (1976) suggested carbonyl sulfide (OCS) as the major precursor gas, although this hypothesis has been challenged (see e.g. Chin and Davis (1995); Leung et al. (2002)). Very recently, increased anthropogenic $\mathrm{SO}_{2}$ emission by coal burning in China has been proposed as a possible origin for an upward trend in lidar measurements of stratospheric aerosols (Hofmann et al., 2009). A good overview of stratospheric aerosol science can be found in (SPARC, 2006).

Polar Stratospheric Clouds have been investigated for over two decades now. The well-known classification scheme of PSCs was originally based on observations of backscatter and depolarization ratios with lidar instruments (Poole and McCormick, 1988). Type Ia particles are believed to be relatively large crystalline particles consisting of hydrates of $\mathrm{HNO}_{3}$ such as Nitric Acid Trihydrate (NAT) or Dihydrate (NAD). The smaller, liquid Type Ib particles consist of a supercooled ternary solution (STS) of $\mathrm{HNO}_{3}, \mathrm{H}_{2} \mathrm{SO}_{4}$ and $\mathrm{H}_{2} \mathrm{O}$. The crystalline Type II particles are formed of pure water ice. PSCs have a crucial role in the stratospheric ozone depletion process over the Arctic and Antarctic regions, because of (1) heterogeneous chemistry on the particle surface and (2) the denitrification of the atmosphere by the sedimentation of mainly Type Ia particles. Formation of PSCs is driven by temperature: Type Ia and Ib particles form below about $195 \mathrm{~K}$, while the Type II ice crystals form at the ice frost point, about 188 to $190 \mathrm{~K}$ in the lower stratosphere. These cold temperatures are provided in the polar regions during local winter. A more detailed description of PSC formation can be found in the review paper of Zondlo et al. (2000).

The so-called subvisual cirrus clouds are a fairly recent discovery for the obvious reason that they are optically thin and thus invisible from the ground (hence the name): an upper limit for the optical thickness of 0.03 at $694 \mathrm{~nm}$ is sometimes mentioned in the literature. Long optical pathlengths ensure that satellite occultation instruments such as SAGE II have detected them frequently (Wang et al., 1996). They are mainly found in the tropics and midlatitudes, around the tropopause altitude region $(16-17 \mathrm{~km})$. Much is still to be learned about the formation of these clouds, but Jensen et al.
(1996) proposed at least two mechanisms: (1) they originate from horizontal anvil-shaped outflows of large convective cumulonimbus clouds, and (2) from nucleation inside a humid layer that experiences slow uplift through the extremely cold region of the tropopause. Subvisual cirrus form cloud layers with a very large horizontal extent (hundreds of kilometers) but are at the same time very thin (smaller than $1 \mathrm{~km}$ ). In recent years they received a lot of attention due to their possible role in the radiative balance of the atmosphere, their impact on ozone concentrations through heterogeneous chemistry (Solomon et al., 1997), and their role in the dehydration of air that enters the tropical lower stratosphere (Jensen et al., 1996).

The Global Ozone Monitoring by Occultation of Stars (GOMOS) instrument was primarily intended to deliver accurate altitude profiles of trace gas concentrations. These retrievals can be performed since each gas is detected by its specific spectral signature in the measured light intensity. Atmospheric particle populations pose a more challenging problem since the spectral shape is unknown, with the direct consequence that it is a priori impossible to find out which kind of particles are in the line of sight of the instrument. This is the reason why GOMOS delivers only one common product, perhaps somewhat misleadingly dubbed "aerosol extinction". It should be understood that this data product currently embraces all above-mentioned types of aerosol and cloud particles (or indeed even any unknown extinction phenomenon with a smooth spectral dependence). However, the distinction will be made in this paper with the use of additional information, such as time of appearance/disappearance, geolocation and altitude.

First results on GOMOS aerosol/cloud extinction profiles representing the year 2003 were previously published (Vanhellemont et al., 2005). The data discussed here span a much longer time period, from 2002 to 2008. Furthermore, a new data version was used, with as most important feature the use of a quadratic polynomial of wavelength as aerosol extinction model, while the previous model as described in (Vanhellemont et al., 2005) was oversimplified and consisted of a fixed inverse wavelength function.

\section{GOMOS: Instrument and obtained data set}

The GOMOS instrument has been adequately described elsewhere (Kyrölä et al., 2004; Bertaux et al., 1991, 2000, 2010), so we only give a brief summary here. GOMOS, onboard ENVISAT, was launched in a sunsynchroneous orbit on 1 March 2002. GOMOS routine operations started in August 2002, and since then the instrument has been recording data almost continuously until present. GOMOS observes occultations of stars (chosen from a predefined catalogue) behind the earth limb, and records the received light intensity in the UV/Vis/NIR spectral range: $248-690 \mathrm{~nm}$ (spectrometers A1 and A2), $755-774 \mathrm{~nm}$ (spectrometer B1) and 926-954 nm 

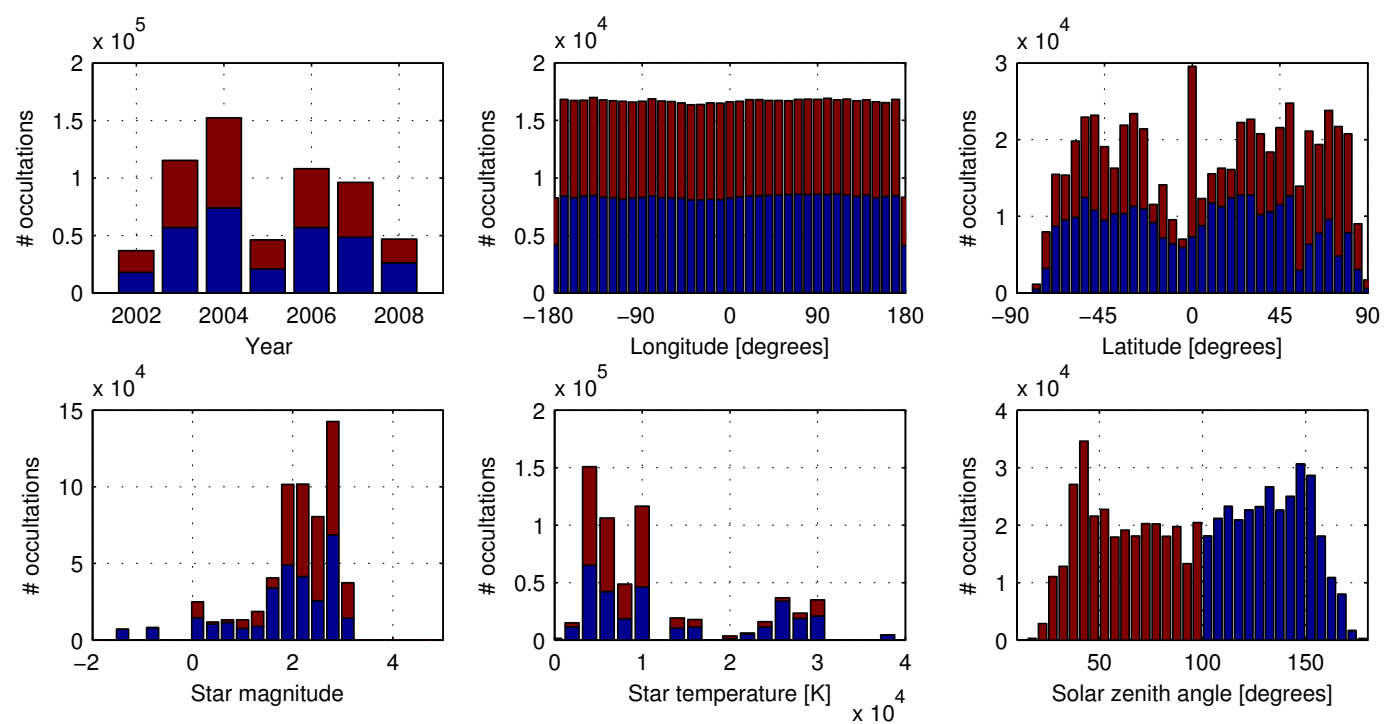

Fig. 1. Occultation statistics for the entire GOMOS data set spanning the period August 2002-May 2008. Shown are histograms representing the number of GOMOS occultations as function of (from left to right, top to bottom) year, longitude, latitude, star magnitude, star temperature and solar zenith angle. Blue histograms refer to the fraction of occultations in dark limb, red ones to the fraction in bright limb.

(spectrometer B2). From measured signals, transmittances are calculated that in turn are used to derive altitude concentration profiles for $\mathrm{O}_{3}, \mathrm{NO}_{2}, \mathrm{NO}_{3}, \mathrm{H}_{2} \mathrm{O}$ and $\mathrm{O}_{2}$, and temperature profiles. Furthermore, aerosol/cloud extinction profiles at different wavelengths are obtained.

The integration time to record a GOMOS full spectrum is $0.5 \mathrm{~s}$. The actual vertical sampling is determined by this time, together with the vertical velocity of the tangent point (between 0.5 and $3.4 \mathrm{~km} / \mathrm{s}$, depending on the obliquity of the occultation) and refraction of the optical path at lower altitudes (which decreases the tangent point vertical velocity). A maximum vertical sampling resolution of $1.7 \mathrm{~km}$ can be expected, but during very oblique occultations a 200 meter sampling is obtained. The actual star spectrum is (in normal mode) calculated from $7 \mathrm{CCD}$ rows of the spectrometers, equivalent to a field of view of 0.01 degrees.

It is important to know that the uncertainty on the obtained profiles is largely determined by the magnitude and temperature of the observed star. But even bright stars (such as Sirius) are weak light sources in comparison with the Sun; profiles obtained from stellar occultations have therefore larger uncertainties than the ones from solar occultations. This disadvantage is however largely compensated for by the fact that stars are abundant in the sky: about 30 to 40 occultations have been typically observed per orbit, although this number decreased to 20 or 30 occultations per orbit after an instrument malfunction in 2005. Hundreds of thousands of occultations have been observed by GOMOS since the start of the mission.
The occultation statistics for the period August 2002 - May 2008 (a total of about 600000 events, the entire data set that was available to us at the time of writing) are represented by histograms in Fig. 1. Of course, the lower number of occultations for the years 2002 and 2008 are caused by an incomplete sampling of these years, while the smaller number in 2005 resulted from the instrument failure mentioned earlier. Longitudinal sampling is clearly very homogeneous. Most occultations occur at midlatitudes, although plenty of polar measurements are available. Most stars have moderate to weak brightness, and are rather cold. Also, about half of the occultations occur in the Sun-illuminated atmosphere ("bright limb", Solar Zenith Angle SZA $<100$ ), the other half in 'dark limb' $(S Z A \geq 100)$. More details about the solar illumination condition and its consequences are given below.

\section{Retrieval method}

\subsection{Spectral behaviour}

As already said above, the particle optical extinction spectrum is a priori unknown. Therefore, the actual optical spectrum is treated as a product of the retrieval algorithm. It is far from clear how such a particle optical spectrum should be parameterized, but we can be guided by the fact that usual atmospheric particle size distributions are broad, covering a few orders of magnitude, and the resulting optical spectra are thus smooth. Hence they are often described with analytic, smooth functions, such as polynomials. For data version 6.0, the GOMOS Science team chose to implement a quadratic 
polynomial as a function of wavelength for the simple reason that it is versatile: large (constant spectrum), medium-sized (peak at mid-visible wavelengths) or small particle spectra (the Rayleigh limit: extinction $\beta$ depends on wavelength $\lambda$ as $\beta \sim \lambda^{-4}$ ) can within good approximation be captured by such polynomials. Retrieval algorithms for other satellite occultation instruments are often also equipped with this feature. Furthermore, Vanhellemont et al. (2006) showed with simulated data (using a Mie code) that a quadratic polynomial is a good choice when one wants to obtain good aerosol retrievals without introducing too many degrees of freedom in the retrieval problem.

\subsection{Spectral/spatial inversion}

The GOMOS retrieval algorithm has been described in detail in another paper of this special issue (Kyrölä et al., 2010). Here it suffices to say that the retrieval consists of two parts: (1) the spectral inversion, where measured transmittance spectra at each tangent altitude separately are inverted to slant path integrated column densities (for gases) and optical thickness (for particles), and (2) the spatial or vertical inversion, where the retrievals of the first step are separately inverted to local concentration profiles (gases) and optical extinction profiles (particles). This second step is performed in combination with a Tikhonov altitude smoothing (Twomey, 1985; Rodgers, 2000) in order to get partially rid of the perturbations caused by residual scintillation in measurements taken during very inclined occultations (Sofieva et al., 2009). The amount of smoothing is determined by a predetermined target resolution for the profile. For particles, a profile resolution of $4 \mathrm{~km}$ was chosen since unsmoothed profiles showed strong oscillations; aerosol extinction spectra have the tendency to swallow a large portion of the residual scintillation perturbations. Nevertheless, fine-scale structures (e.g. thin clouds) are smeared out due to this feature. The choice of $4 \mathrm{~km}$ for target resolution was based on the experience that it gave agreeable results; the actual magnitude of the residual scintillation perturbation on aerosol profiles is still not adequately determined, although it is known for the ozone retrievals (Sofieva et al., 2009).

It is in the spectral inversion model that the slant path particle optical thickness is implemented as a quadratic polynomial:

$$
\tau(\lambda)=\sigma_{\text {ref }}\left(r_{0}+r_{1} \Delta \lambda+r_{2} \Delta \lambda^{2}\right)
$$

with $\Delta \lambda=\lambda-\lambda_{\text {ref }}$ and $\lambda_{\text {ref }}=500 \mathrm{~nm}$ a reference wavelength. For scaling purposes, a "cross section" $\sigma_{\text {ref }}=6 \times 10^{-10} \mathrm{~cm}^{2}$ was used. Notice that only the first parameter $r_{0}$ has a direct physical meaning: $\sigma_{\text {ref }} r_{0}$ equals the particle slant path optical thickness at $500 \mathrm{~nm}$. During the spatial inversion, this parameter receives Tikhonov-style altitude smoothing, while the other parameters remain unconstrained. Retrospectively, this turned out to be a poor methodology: while the obtained extinction profiles at $500 \mathrm{~nm}$ look quite good, the spectra at other wavelengths (evaluated with the quadratic polynomial within the spectrometer A range 248-690 nm) are often very noisy.

Finally, it should be mentioned that during the spectral inversion, the optical extinction spectra from the neutral air (Rayleigh scattering) are removed instead of retrieved from the measurements, using external ECMWF (European Centre for Medium-range Weather Forecasts) air density data, to avoid interferences with the residual scintillation and the spectrally similar aerosol contribution. Also, only spectrometer A measurements are currently used for the aerosol retrieval.

\subsection{The homogeneous layer assumption}

Occultation measurements have a limited information content. Hence the assumption of homogeneous atmospheric layers that is so often found in retrieval codes: the number of unknowns is drastically reduced, leading to a more stable inversion. For more or less uniformly mixed gases and particles (such as stratospheric aerosols), the assumption should hold quite well. However, when local phenomena (such as clouds) are observed, the assumption is wrong: the phenomenon affects the light ray only locally. This should be taken into account whenever we analyse retrievals of PSCs and volcanic plumes, for example: the obtained extinction coefficients should be seen as slant path equivalent values.

\subsection{Bright limb versus dark limb retrievals}

When the optical light path traverses the Sun-illuminated atmosphere, parts of the atmosphere located in the fieldof-view scatter additional light into the instrument, which means that the simple optical transmission model for the retrieval is not correct anymore. This was anticipated: the additionnal upper and lower CCD bands in GOMOS were implemented to correct for this background illumination (Bertaux et al., 2010; Kyrölä et al., 2010). However, post-launch processing showed that the correction is not perfect. The situation is particularly bad for the aerosol extinction profiles, since their smooth optical extinction spectrum strongly resembles the limb signal. The aerosol extinction retrievals typically show unrealistic features at very high stratospheric altitudes. At present, the best we can do is exclude the bright limb profiles from data analysis. Investigations showed that occultation events with a solar zenith angle of $100^{\circ}$ or larger deliver unperturbed, dark limb aerosol retrievals.

\subsection{Retrieval results}

In summary, the GOMOS particle extinction profiles have acceptable quality around $500 \mathrm{~nm}$, but are oversmoothed. At other wavelenghts, the profile quality is poor, and we therefore exclude them from further study. Furthermore, it is best to exclude the aerosol profiles in bright limb 

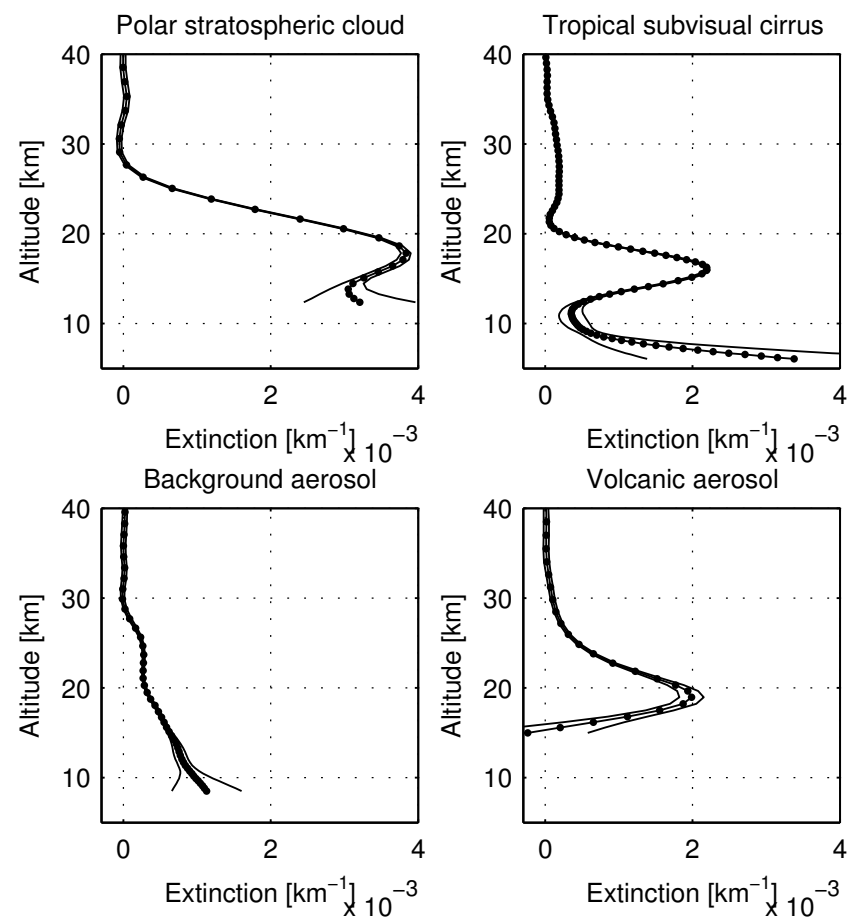

Fig. 2. Individual GOMOS particle extinction profiles with associated uncertainty: a Polar Stratospheric Cloud (30/7/2003, 72,57 ${ }^{\circ}$ S, $\left.2.18^{\circ} \mathrm{W}\right)$, a tropical subvisual cirrus cloud $\left(7 / 10 / 2002,0.52^{\circ} \mathrm{S}\right.$, $\left.78.69^{\circ} \mathrm{E}\right)$, background stratospheric aerosols $\left(12 / 9 / 2003,43.34^{\circ} \mathrm{S}\right.$, $\left.137.36^{\circ} \mathrm{W}\right)$, volcanic stratospheric aerosols $\left(9 / 1 / 2007,4.52^{\circ} \mathrm{S}\right.$, $27.15^{\circ} \mathrm{E}$ ). All plots have the same scale, in order to facilitate comparisons of magnitude.

$(\mathrm{SZA}<100)$ : from the entire data set of 600000 occultations, about 301000 remain to be exploited. Among these, some are still perturbed by residual scintillation. These perturbations are visible in individual aerosol extinction profiles. When averaging large numbers of profiles (see e.g. the zonal plots below), the resulting mean profile becomes smooth. There is reason to assume that the scintillation perturbations do not introduce bias in the extinction profiles, as comparisons with other instruments show (see below).

Like all profiles derived from occultation measurements, GOMOS aerosol extinction profiles are increasingly more uncertain when we descend to lower altitudes, because the transmitted light intensity becomes weaker due to increasing atmospheric extinction by gases, aerosols and clouds. In principle, a cut-off altitude can be defined, below which no aerosol information is present anymore. This altitude depends on the wavelength considered, and the magnitude and temperature of the star, and therefore changes from one occultation to the next. At $500 \mathrm{~nm}$, an average limit of $10 \mathrm{~km}$ can be considered as a rough estimate below which the profiles are not trustworthy anymore.
On Fig. 2, we present individual GOMOS extinction retrievals at $500 \mathrm{~nm}$ for a number of particle types. It is impossible to distinguish these types using only one wavelength; the presented profiles were selected after analysis of the entire GOMOS data set and knowledge about geolocation and time of occurence of these particle phenomena (see further on in this paper).

It is clear that the profiles are oversmoothed. For instance, tropical subvisual clouds are known to be horizontally extended cloud layers that are quite thin, having a thickness smaller than $1 \mathrm{~km}$ (Jensen et al., 1996); the example on the figure clearly shows that the layer has been spread out by the smoothing constraint.

We should mention here that the obtained particle extinction retrievals sometimes assume negative values, usually at altitudes where the measured signals are low (below the above-mentioned cut-off altitude), or where the particle abundance is low (upper stratosphere and higher). This is a logical consequence of the fact that the last retrieval step (spatial inversion) is linear and that the retrievals are not constrained to be positive. All further results that are discussed in this paper were obtained by processing of data that include negative values; discarding these would lead to biased results.

Quantifying the aerosol extinction retrieval error is challenging. A detailed description can be found in another paper of this GOMOS special issue (Tamminen et al., 2010). We repeat the most important ideas and findings here. The random error on a profile is determined by two contributions that we mentioned before: (1) the measurement noise which changes from one stellar source to another due to star magnitude and temperature differences, and (2) the uncorrected residual scintillation component. At the time of writing the GOMOS error estimation for the operational data products does not yet take the latter into account, so that retrieval errors are likely underestimated. The influence of star magnitude is clear: brighter stars deliver a better signal-to-noise ratio. Star temperature determines the main spectral emission range: hot stars emit in the UV, colder ones in the visible and near-infrared domain. The influence of star temperature on aerosol retrievals nevertheless remains limited; it is star magnitude that plays the crucial role (Tamminen et al., 2010). Sources of systematic error are of course (1) a possibly wrong aerosol spectral model, and (2) an imperfect ECMWF air density profile, both of which have been estimated by Tamminen et al. (2010). Retrieval errors are of course calculated by standard error propagation through the retrieval chain. Aerosol extinction error estimates (for bright stars) of $30 \%$ are obtained around an altitude of $10 \mathrm{~km}, 2$ $10 \%$ from 15 to $25 \mathrm{~km}$, and $10-50 \%$ from 25 to $40 \mathrm{~km}$.

As mentioned before, the amount of Tikhonov altitude smoothing is determined by a predefined target resolution of $4 \mathrm{~km}$, at all altitudes, regardless of the star magnitude and temperature. Presentation of averaging kernels is therefore unnecessary; the profile resolution is chosen in advance. 

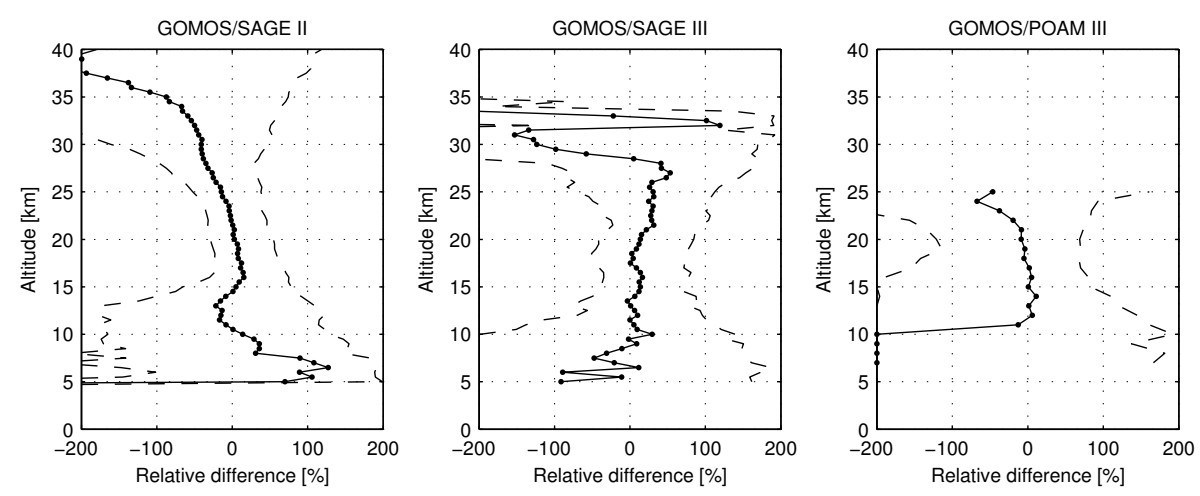

Fig. 3. Comparison of GOMOS aerosol extinction profiles with other satellite measurements: SAGE II at $525 \mathrm{~nm}$ (left panel), SAGE III at $596 \mathrm{~nm}$ (middle panel) and POAM III at $603 \mathrm{~nm}$ (right panel). Shown are the statistics for the relative differences, calculated as $100 \times 2\left(p_{\mathrm{GOMOS}}-p_{\mathrm{SAT}}\right) /\left|p_{\mathrm{GOMOS}}+p_{\mathrm{SAT}}\right|$. The median of the set of relative differences is shown with full lines and dots. Dashed lines indicate the spread, given by the 16 th and 84 th percentile.

\section{Comparisons with other instruments}

A detailed validation study for the GOMOS aerosol extinction profiles has not been performed yet. Nevertheless, Vanhellemont et al. (2008) already performed comparisons with the results derived from the imagers of the Atmospheric Chemistry Experiment ACE (Bernath et al., 2005). Here, we present first comparisons with aerosol extinction profiles from the Stratospheric Aerosol and Gas Experiment II (SAGE II; see Chu et al. (1989)), its follow-up SAGE III (Thomason and Taha, 2003) and the Polar Ozone and Aerosol Measurement POAM III (Lucke et al., 1999). As already stated, only dark limb measurements were considered. Furthermore we avoided PSCs by excluding occultations inside the polar vortex: apart from the wrong assumption of homogeneous layers, two different instruments with two different viewing geometries will deliver two different profiles for the same cloud. This is less of a problem for tropical subvisual cirrus since they typically have a very wide horizontal extent and are very thin. A coincidence window of $+/-250 \mathrm{~km}$ and $+/-6 \mathrm{~h}$ was used, allowing us to find a fairly large comparison data set, summarized in Table 1. The geographic location of the obtained coincidences is mainly determined by the coverage of the used instruments (SAGE II, SAGE III and POAM III) since GOMOS has a near-global coverage with several occultation latitudes per orbit. Notice that we used a spectral channel of each instrument that is close to the GOMOS reference wavelength of $500 \mathrm{~nm}$. Furthermore, GOMOS data were interpolated to these wavelengths using the retrieved quadratic polynomial. We should also mention that no effort was made to match the vertical resolution between two instruments with averaging kernels; this will certainly be done in a full validation study in the future.
For the $i$-th coincidence, the difference between GOMOS (GOM) and the other instrument (SAT), relative to the mean of the two, was evaluated as follows:

$\Delta_{i}=100 \times 2 \frac{\left(p_{\mathrm{GOM}, i}-p_{\mathrm{SAT}, i}\right)}{\left|p_{\mathrm{GOM}, i}+p_{\mathrm{SAT}, i}\right|}$

As statistical estimators for the entire data set, we prefered to use the median (50th percentile) since it is more robust with respect to outliers than the numerical mean. The variance of the data set was calculated with the 16th and 84th percentile. The obtained statistical estimates are shown in Fig. 3. As can be seen, the comparisons are quite good at upper tropospheric/lower stratospheric altitudes. Differences with SAGE II are within $20 \%$ from 10 to $25 \mathrm{~km}$, a conclusion that can also be drawn for the SAGE III comparisons. The median differences with POAM III are even smaller, within $10 \%$ from 11 to $22 \mathrm{~km}$. Notice however that the variance is much larger than for the SAGE II/III comparisons.

\section{Results}

\subsection{Yearly zonal statistics}

A coarse idea about the presence of aerosols and clouds in the upper troposphere/lower stratosphere can be gained by considering zonal yearly statistics. Ranging from $90^{\circ} \mathrm{S}$ to $90^{\circ} \mathrm{N}, 72$ latitude bins with a width of 2.5 degrees were defined. Aerosol extinction profiles were linearly interpolated on a common altitude grid ranging from 1 to $50 \mathrm{~km}$ with a spacing of $1 \mathrm{~km}$. Yearly statistics were subsequently calculated on all data within one bin. Once again: we used percentiles as statistical estimators since extinction values are not necessarily normally distributed and because the median (50th percentile) is rather insensitive to outliers. We should 
Table 1. GOMOS aerosol extinction retrievals: comparison data set; coincidence window: (500 km, $1 / 2$ day)

\begin{tabular}{lcccc}
\hline Instrument & Version & Wavelength & \# of coincidences & Time period considered \\
\hline SAGE II & 6.20 & $525 \mathrm{~nm}$ & 6227 & 27 August 2002-March 5, 2005 \\
SAGE III & 3.00 & $596 \mathrm{~nm}$ & 6258 & 7 November 2002-3 December 2005 \\
POAM III & 4.00 & $603 \mathrm{~nm}$ & 11641 & 26 August 2002-3 December 2005 \\
\hline
\end{tabular}
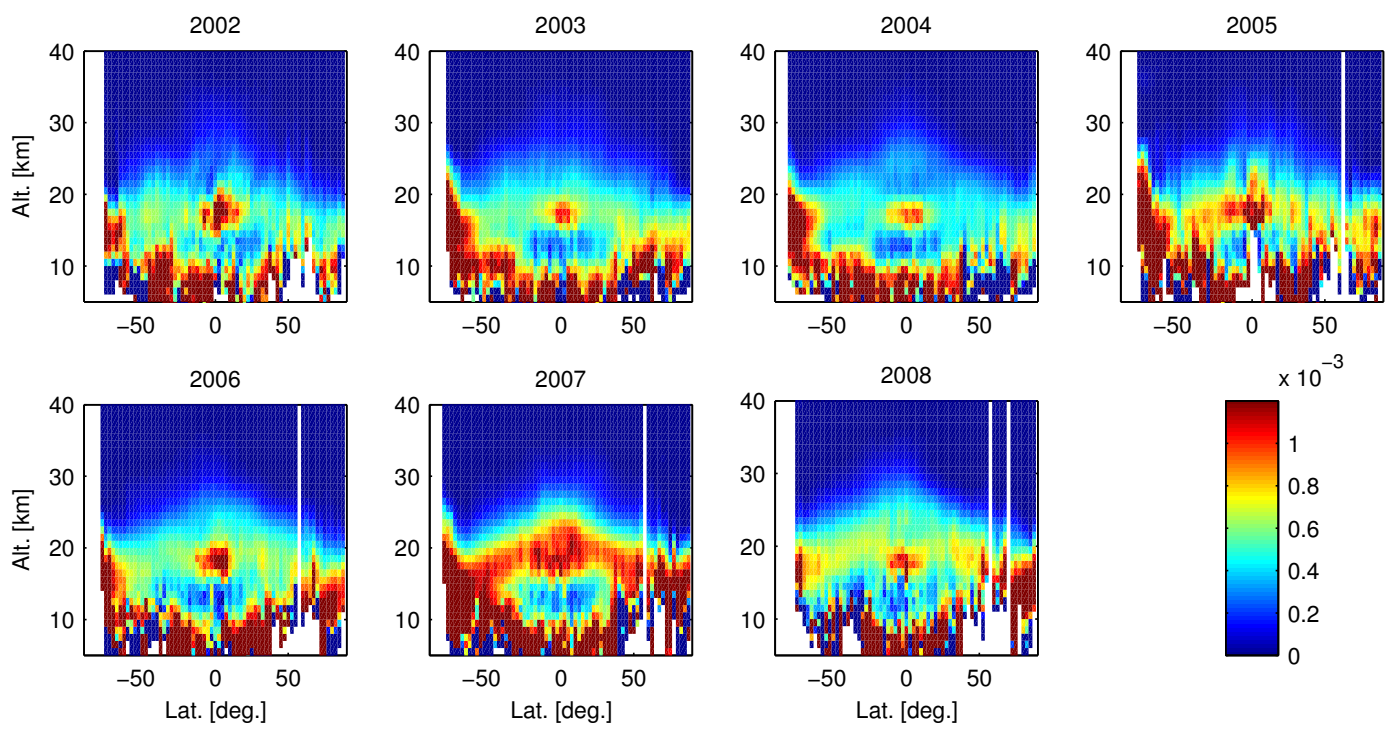

Fig. 4. Yearly zonal median values of (dark limb) aerosol extinction at $500 \mathrm{~nm}$ for the entire GOMOS mission. All features that are to be expected are present: the stratospheric aerosol layer, PSCs in the Antarctic region, tropical subvisual cirrus clouds. Notice the enhanced stratospheric aerosol layer in 2007, resulting from the Soufrière Hills eruption in May 2006. Years that are sampled incompletely: 2002 (start of the data set: August 2002), 2005 (instrument failure) and 2008 (end of available data set).

also mention that yearly zonal statistics are seasonally biased when we use only dark limb measurements, since Arctic/Antarctic summer is not sampled. The median particle extinction at $500 \mathrm{~nm}$ is shown in Fig. 4 for every GOMOS mission year. A few phenomena are readily observed: (1) the umbrella-shaped stratospheric aerosol layer that is highest at the equator, lowest at the poles, (2) higher extinction values in the Antarctic (and to a lesser extent Arctic) stratosphere that are caused by PSCs, and (3) higher extinction values in a localized tropical zone at an altitude of about 16$17 \mathrm{~km}$ due to subvisual cirrus clouds. The picture is almost systematic for every year, but there are some significant differences however. First notice that Antarctic PSCs are less pronounced for the years 2002 and 2008 because the Antarctic PSC season is not well sampled in those years: the data set starts end of August 2002 and ends in May 2008. More important, stratospheric aerosol extinction levels are much higher in 2007 and remain elevated even in 2008, suggesting the formation of new aerosols following stratospheric injection of $\mathrm{SO}_{2}$ by a volcanic eruption. This is the case; the Soufrière Hills eruption (see below) in May 2006 is most likely the source. Furthermore, 2005 also seems to exhibit elevated aerosol levels, although the picture is noisier due to the incomplete sampling of the year (instrument failure).

Equally interesting is the yearly zonal variability of the $500 \mathrm{~nm}$ aerosol extinction values, calculated as half the difference between the 84th and 16th percentile. The variability is of course determined by the $\mathrm{S} / \mathrm{N}$-ratio of the measurements and (more importantly) by natural aerosol/cloud variability, caused by the appearing, disappearing and atmospheric transport of particles. This is clearly visible on Fig. 5. Typical "on/off-events" such as clouds (tropical cirrus, PSCs) exhibit large variability, while slowly changing features (such as the stratospheric aerosol layer) vary little within one year. Notice once again that the Antarctic PSC variability during 2002 and 2008 is weak since these years have not been completely sampled. At lower, tropospheric altitudes, we see large variability due to a combination of larger profile uncertainty (measured signals are weaker) and tropospheric clouds. 

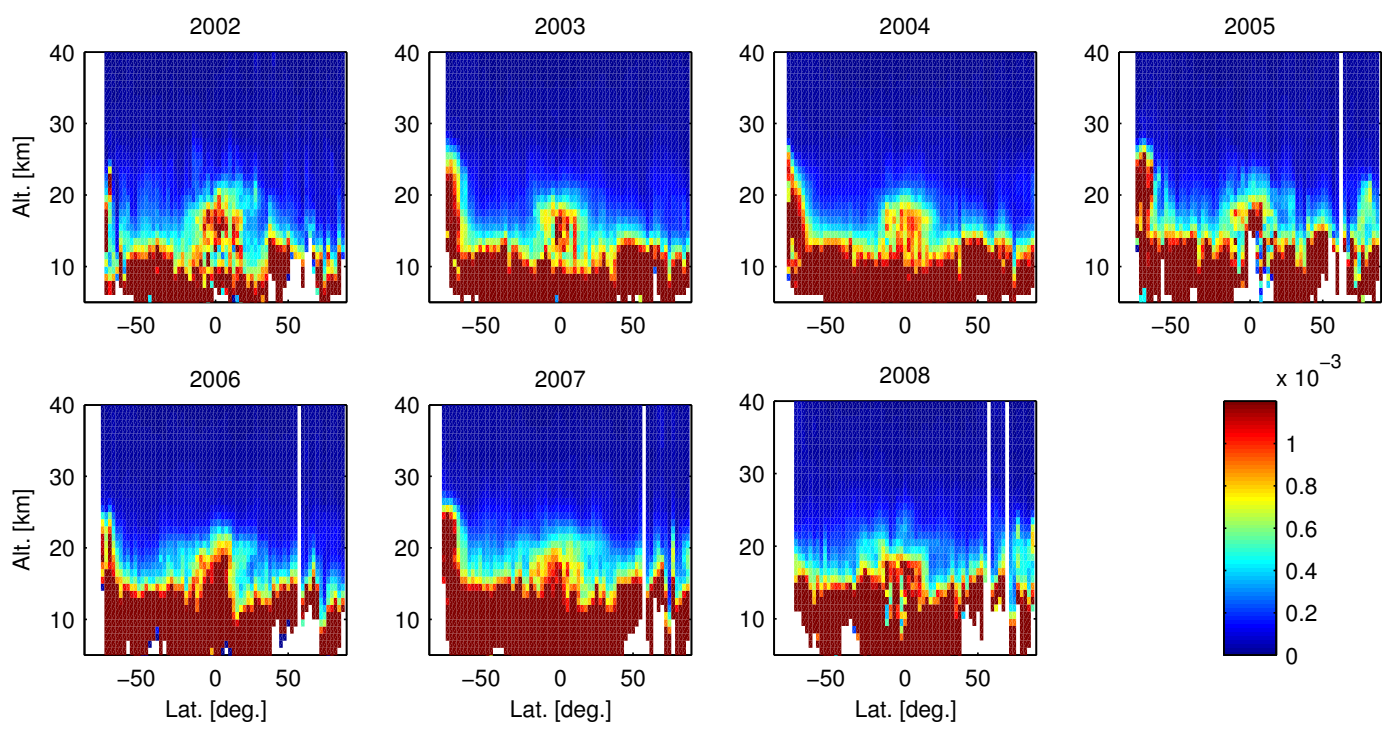

Fig. 5. Yearly zonal variability of (dark limb) aerosol extinction at $500 \mathrm{~nm}$ for the entire GOMOS mission. Variability is calculated as half the difference of the 84th and 16th percentile, and is determined by measurement error and (more importantly) by natural aerosol/cloud variability. "On/off" events such as clouds (tropical cirrus, Antarctic PSCs) of course exhibit large variability, while slowly changing features (backgrounds aerosol layer) vary little. Years that are sampled incompletely: 2002 (start of the data set: august 2002), 2005 (instrument failure) and 2008 (end of available data set).

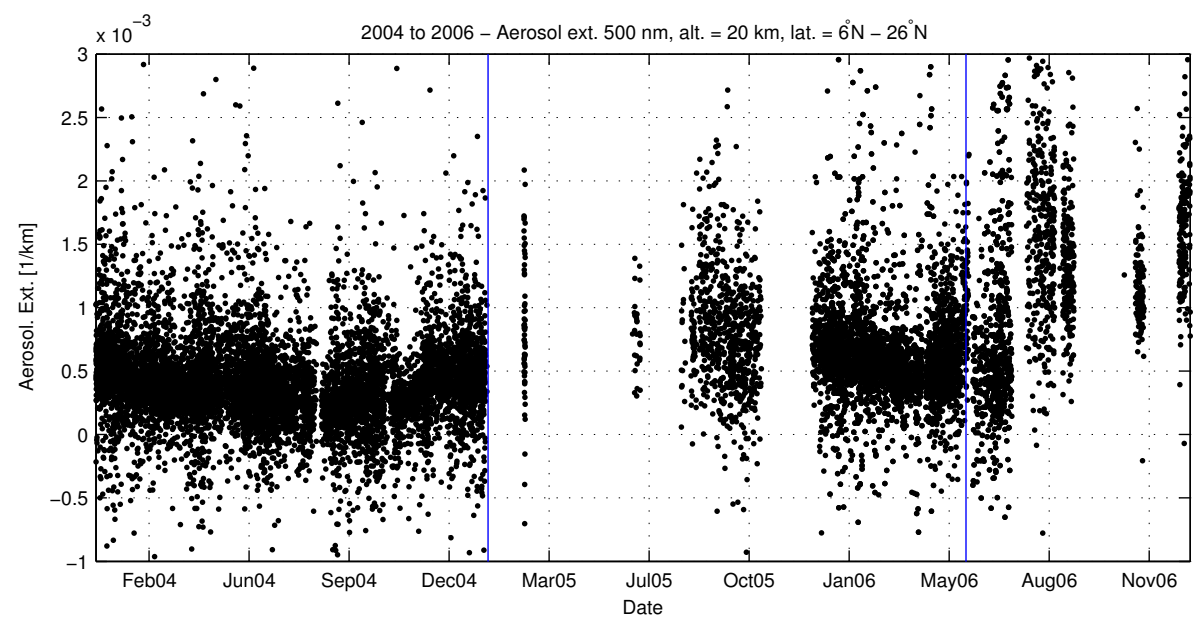

Fig. 6. A 2004-2006 GOMOS aerosol extinction time series at an altitude of $20 \mathrm{~km}$. All data within a latitude band from $6-26^{\circ} \mathrm{N}$ are shown. Clearly visible are the background aerosol condition in 2004, the possible declining tail of the post-eruptive aerosols resulting from the Manam volcano (Papua New Guinea, Jan. 27-28, 2005; first vertical line), and the enhanced aerosol levels following the eruption of Soufrière Hills (Montserrat, 20 May 2006, second vertical line).

\subsection{Volcanic stratospheric aerosols}

The observed elevated extinction levels in 2005 and 2007 require a more detailed investigation. On Fig. 6, we present aerosol extinction values at an altitude of $20 \mathrm{~km}$ (which lies above the subvisual cirrus altitudes) for the period 20042006 , in a tropical latitude band from $6^{\circ} \mathrm{N}$ to $26^{\circ} \mathrm{N}$. Three distinct periods can be seen. First, we observe low background aerosol levels until the end of 2004. Second, from early 2005 to the beginning of June 2006, large data gaps are present due to instrument failure. Nevertheless, the data seem to suggest a declining tail following a volcanic eruption, especially if we take the small set of data points at early 2005 into account. And third, in early July 2006 we observe 

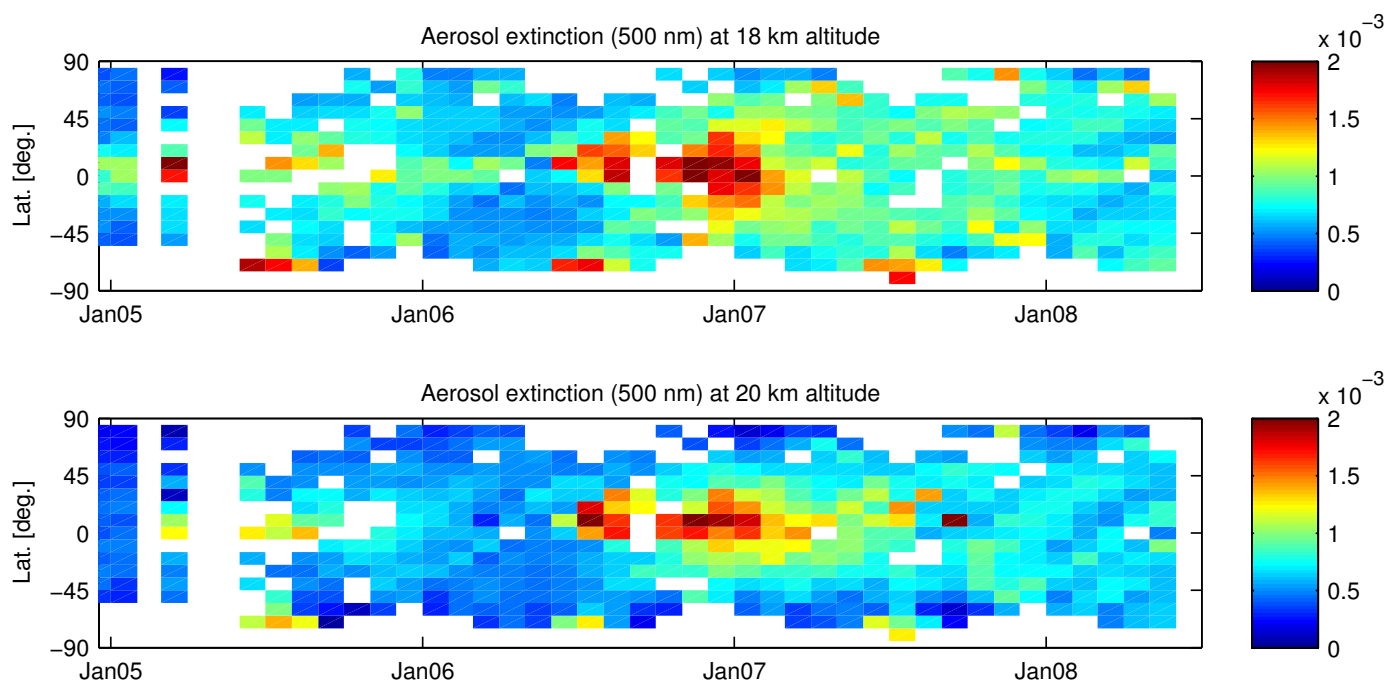

Fig. 7. Checkerboard plots showing the median of binned $500 \mathrm{~nm}$ aerosol extinction data as function of latitude and time, at an altitude of $18 \mathrm{~km}$ (upper panel) and $20 \mathrm{~km}$ (lower panel). Notice the elevated values after early 2005, and after the end of May 2006 . The global spreading is clearly visible in the latter case.

a sudden increase by about a factor of 3 in extinction levels. The same conclusions are drawn when inspecting the evolution in latitude and time on Fig. 7. It is clear that at least two volcanic events in the tropics should be considered.

The elevated values in 2005 are most likely caused by stratospheric sulfate aerosols, formed out of the $\mathrm{SO}_{2}$ cloud injected in the stratosphere by the eruptions of the Manam volcano (Papua New Guinea, $4.080^{\circ} \mathrm{S}, 145.037^{\circ} \mathrm{E}$ ) on January 27 and 28 (Kamei et al., 2006). Manam is one of the most active volcanoes in the region; the above mentioned eruptions followed ongoing volcanic activity that started already in October 2004. An image taken by the infrared Aqua/MODIS (Moderate Resolution Imaging Spectroradiometer) indicates that the ash clouds of the first eruption on 27 January reached to over $20 \mathrm{~km}$ altitude, well into the stratosphere. The ash clouds of the second eruption on Jan. 28 ascended to $18 \mathrm{~km}$ altitude (Smithsonian Institution, 2005). Several days later, stratospheric aerosol layers were detected twice between about 18 to $20 \mathrm{~km}$ altitude (layer thickness ranging from 0.2 to $1.4 \mathrm{~km}$ ) by a shipboard lidar using a Nd:YAG laser operated at $1064 \mathrm{~nm}$ and $532 \mathrm{~nm}$ (Kamei et al., 2006). The layers were detected in the Western Pacific around $0-2^{\circ} \mathrm{N}, 156^{\circ} \mathrm{E}$ (3-4 February 2005) and 7$9^{\circ} \mathrm{N}, 156^{\circ} \mathrm{E}$ (9-10 February). Inspecting Fig. 7, we see that the amount of injected sulfur was large enough to leave a significant aerosol trace in the GOMOS data during the largest part of 2005.

The source for the elevated aerosol levels in the second half of 2006 and 2007 has been identified as the eruption of the Soufrière Hills volcano $\left(16.72^{\circ} \mathrm{N}, 62.18^{\circ} \mathrm{W}\right.$, Montserrat, West Indies), on 20 May 2006. Immediately following the collapse of the eastern volcano flank, an eruption column of ash and gases rose to at least $17 \mathrm{~km}$. Prata et al. (2007) used a combination of satellite instruments (Aqua/AIRS, MSG/SEVIRI, MLS, OMI and CALIPSO/CALIOP) to reconstruct the event and its immediate aftermath. They found that an estimated $0.1 \mathrm{Tg}(\mathrm{S})$ was injected in the stratosphere in the form of $\mathrm{SO}_{2}$, after which the gas cloud traveled westward at an altitude of about $20 \mathrm{~km}$. Carn et al. (2007) on the other hand used OMI data to obtain an estimated $0.22 \mathrm{Tg}$ of $\mathrm{SO}_{2}$. They also reported CALIPSO/CALIOP lidar backscatter measurements of the associated stratospheric aerosol layer as early as 7 June 2006, at an altitude of $20 \mathrm{~km}$. The layer remained visible in the CALIOP data until 6 July. However, as Thomason et al. (2007) remarked, in general the stratospheric aerosol layer remains quite invisible in CALIOP backscatter measurements, while occulation instruments such as SAGE II have no problem with the detection. No doubt this is caused by the preferential forward scattering of light by small particles, in combination with longer optical path lengths. Nevertheless, very recently Vernier et al. (2009) showed how CALIPSO/CALIOP backscatter data improved strongly after the introduction of a new cloud mask and a new calibration, and how an improved stratospheric aerosol picture emerged after sufficient data averaging. In any case, the fact that GOMOS identifies stratospheric sulfate aerosols well after the eruption date is illustrated in Fig. 8, which shows the appearing and poleward transport of the sulfuric acid particles.

Figures 7 and 8 also indicate that it took roughly one year for the Soufrière Hills aerosol cloud to cover the entire globe. Elevated extinction levels remained present until at least the end of 2007. In the months following the Soufrière Hills eruption, a few other eruptions possibly impacted the 

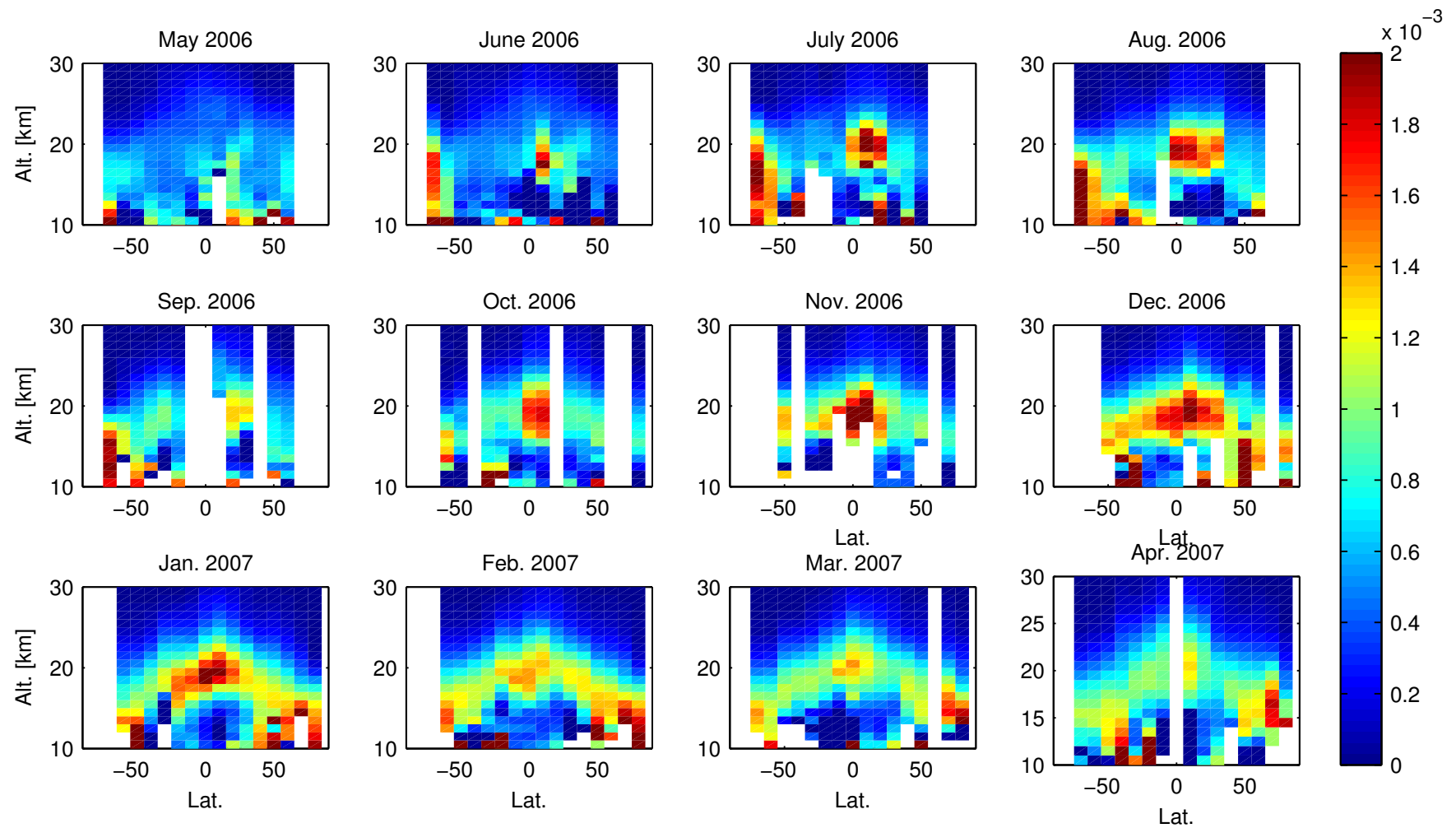

Fig. 8. Evolution of the volcanic stratospheric aerosols resulting from the Soufrière Hills eruption on 20 May 2006 . Shown are monthly zonal median aerosol extinction coefficients at $500 \mathrm{~nm}$. Starting from the eruption site (Montserrat, $16.72^{\circ} \mathrm{N}, 62.18^{\circ} \mathrm{W}$ ), the plume disperses poleward and encircles the entire earth within a year.

stratospheric aerosol layer. Hofmann et al. (2009) briefly mentioned the 14 July 2006 Tungurahua eruption (Ecuador, $\left.1,467^{\circ} \mathrm{S}, 78,442^{\circ} \mathrm{W}\right)$, less than a month after the Soufrière Hills eruption. And Thomason et al. (2007) showed CALIOP observations of the volcanic plume resulting from the October 7, 2006 Tavurvur eruption (Rabaul, Papua New Guinea, $\left.4.271^{\circ} \mathrm{S}, 152.203^{\circ} \mathrm{E}\right)$. Both are equatorial volcanoes that possible injected sulfur into the stratosphere, hereby enhancing the already existing Soufrière Hills perturbation. The Tavurvur case was recently demonstrated in a convincing way using the improved CALIPSO/CALIOP data by Vernier et al. (2009). From GOMOS data it is at present unclear wether or not the existing volcanic aerosol layer was replenished with new sulfate aerosols originating from these eruptions.

\subsection{Polar Stratospheric Clouds}

GOMOS detects PSCs quite well. Strongly enhanced optical extinction is measured every year in the Antarctic PSC season (roughly from the end of May to October), with values typically 3 or 4 times larger than in normal background conditions. These kind of criteria (latitude, time of year, extinction values above a certain treshold) allow us to identify the presence of a PSC. It is however temperature that is the main driver for the formation of PSCs, as can be seen on the top panel of Fig. 9. Shown are all GOMOS aerosol extinction measurements at $500 \mathrm{~nm}$ taken in 2004 at an altitude of $20 \mathrm{~km}$ for the latitude band from $90^{\circ} \mathrm{S}$ to $55^{\circ} \mathrm{S}$. Temperature data were obtained from the GOMOS product files and consist of ECMWF analysis profiles. The selected data set represents a mixture of measurements inside and outside the Antarctic vortex (PSCs and stratospheric aerosols), but plotted against temperature the differentiation is very clear: clouds are formed below about $195 \mathrm{~K}$, the known formation temperature of NAT and STS PSCs. It is however less clear from the data whether or not Type II PSCs form at even lower temperatures. Ideally, differentiation of different types of PSC with UV/Vis/NIR data should be done by inspecting particle size distributions, or the shape of the associated optical spectrum. Methods have already been devised in the past for the SAGE and POAM instruments to make a distinction between Type Ia and Ib particles, based on the assumption that the latter are smaller than the former, with a different extinction spectrum as a consequence (Strawa et al., 2002; Poole et al., 2003). The second panel of Fig. 9 shows the ratio of $600 \mathrm{~nm}$ to $400 \mathrm{~nm}$ GOMOS optical extinction. Theoretically, very small particles $\left(\beta(\lambda) \sim \lambda^{-4}\right)$ should lead to a 
value of 0.2 , while large particles $(\beta(\lambda)=$ constant) should have a value of 1 . The data are extremely noisy due to the already mentioned problem with the aerosol spectral law implementation. Nevertheless, the data cloud is more or less situated between the theoretical limits, and larger particles are observed below $195 \mathrm{~K}$, as expected. The data show also that it is currently impossible to differentiate between different PSC types.

The presented PSC results do not add significantly new information to the current knowledge on PSC formation; for this, much more detailed analysis is needed (taking into account all thermodynamic parameters and air parcel dynamics). But the GOMOS measurements clearly contain elements (temperature dependence of extinction and particle sizes) that are crucial in such a detailed study.

\section{Conclusions}

The current GOMOS operational aerosol/cloud product consists of optical extinction profiles at $500 \mathrm{~nm}$ and additional spectral coefficients to evaluate the extinction at other wavelengths as well. The quality of the product is not optimal yet, due to a problematic spectral law implementation, combined with an altitude smoothing that is too strong. Furthermore, profiles derived from bright limb measurements are currently not usable. Nevertheless, if we restrict ourselves to the use of $500 \mathrm{~nm}$ extinction profiles retrieved from dark limb measurements, then the quality can be considered as good, although fine structure (thin cirrus clouds, cloud inhomogeneities etc.) has been smoothed. For the first time, a comparison with SAGE II, SAGE III and POAM III was presented, showing good agreement within $20 \%$ in the upper troposphere/lower stratosphere, from $10 \mathrm{~km}$ to about $25 \mathrm{~km}$.

All the atmospheric particle types that are expected to be observed by a satellite occultation instrument have been detected by GOMOS: the background stratospheric sulfate aerosol layer (or Junge layer) with its typical umbrellashaped form, sulfate aerosols from volcanic origin, tropical subvisual cirrus clouds just below the tropopause at an altitude of about $16-17 \mathrm{~km}$, and PSCs in the polar regions. The cloud-type events (PSCs and cirrus) have a strong yearly variability, while the Junge layer remains remarkably constant within one year.

The last major volcanic $\mathrm{SO}_{2}$ injection into the stratosphere dates already from almost 18 years ago (Mount Pinatubo, 1991), with the consequence that current aerosol levels are extremely low. So low that the effect of "moderate" volcanic eruptions becomes visible in the GOMOS aerosol record. One might wonder if the so-called background is not only maintained by the typically mentioned sources (OCS, recently even anthropogenic sulfate from coal burning in China), but as well by these moderate volcanic eruptions, that are much weaker than the catastrophic events (Mt. Pinatubo, Mt. St. Helens, El Chichón), but much more frequent. Here,
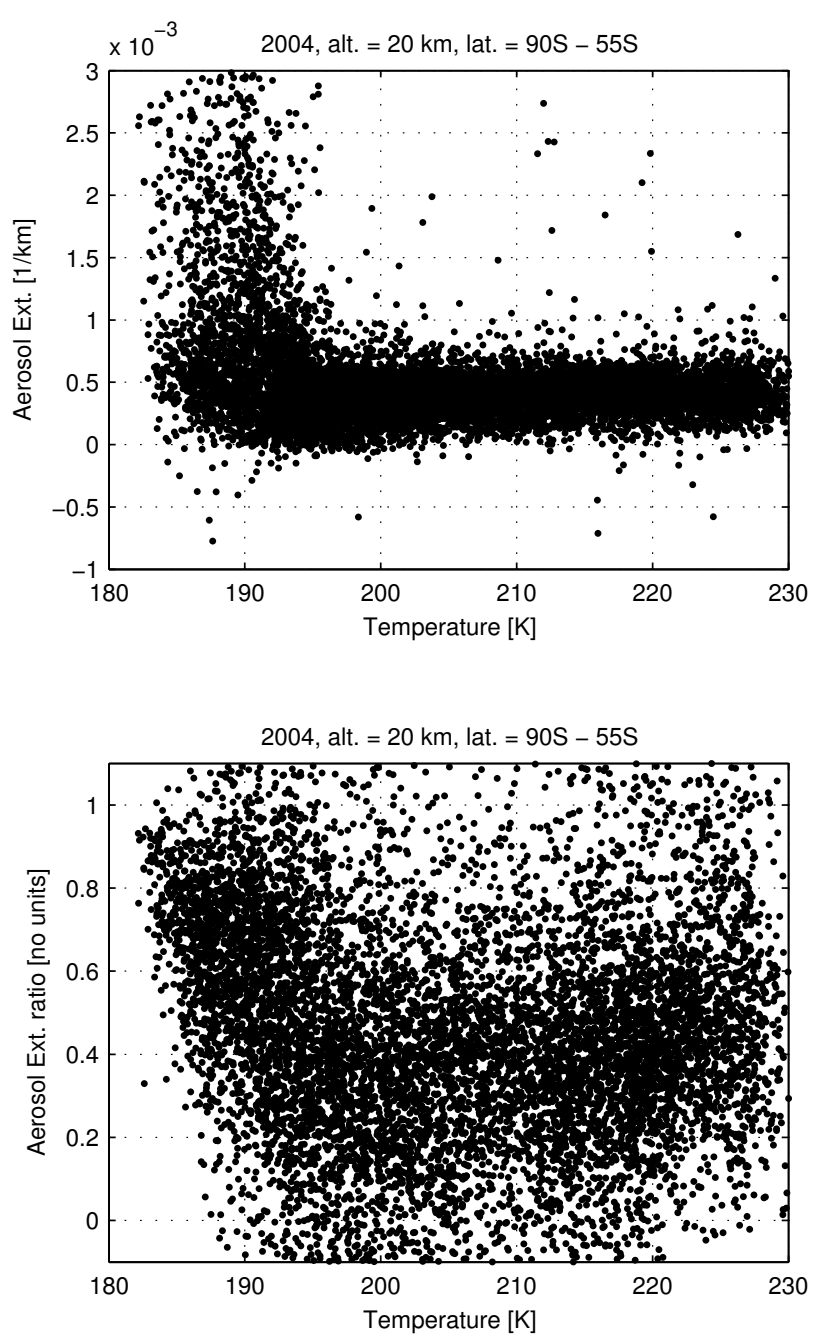

Fig. 9. GOMOS measurements of Polar Stratospheric Clouds. Top panel: optical extinction at $500 \mathrm{~nm}$ versus temperature at an altitude of $20 \mathrm{~km}$, for all dark limb occultations in 2004 at latitudes below $55^{\circ} \mathrm{S}$. Bottom panel: extinction ratio $(600 / 400 \mathrm{~nm})$, derived from the same measurements.

for the first time, the aerosol enhancements resulting from the eruptions of Manam (Papua New Guinea) and Soufrière Hills (Montserrat, West Indies) have been identified in the GOMOS data. In the latter case, GOMOS was clearly able to track the global dispersion of the aerosols. In the aftermath of the eruption, two other possible intrusions should in principle be visible: Tungurahua (Ecuador) and Tavurvur (Papua New Guinea). We hope to identify them in future aerosol profile improvements.

The dynamics of PSCs have been studied previously with GOMOS data (Vanhellemont et al., 2005). The dependence of PSC formation on temperature is a complex study topic. In this paper, we only showed a first qualitative analysis with GOMOS data, the results of which agree with the theoretical 
PSC temperature dependence. The data show also roughly that particle size information is present in the GOMOS data. This is an important conclusion for future studies on the microphysics of PSCs.

As of February 2009, our team has been involved in a new project (AERGOM, an ESA financed project) to develop an improved algorithm that should deliver significantly better aerosol extinction profiles (at all GOMOS wavelengths) in the close future. A cloud-type identification method will also be devised. This will enable us to derive particle size distributions, and to study the microphysics of the observed particle phenomena.

Acknowledgements. This work came into existence with the financial aid of the Belgian Federal Science Policy Office (BELSPO) and the European Space Agency (ESA) through the AERGOM project (Contract No. 22022/08/I-OL). ENVISAT is an ESA mission and GOMOS is an EFI (ESA Funded Instrument).

Edited by: D. Murtagh

\section{References}

Bernath, P. F., McElroy, C. T., Abrams, M. C., Boone, C. D., Butler, M., Camy-Peyret, C., Carleer, M., Clerbaux, C., Coheur, P.-F., Colin, R., DeCola, P., DeMazière, M., Drummond, J. R., Dufour, D., Evans, W. F. J., Fast, H., Fussen, D., Gilbert, K., Jennings, D. E., Llewellyn, E. J., Lowe, R. P., Mahieu, E., McConell, J. C., McHugh, M., McLeod, S. D., Michaud, R., Midwinter, C., Nassar, R., Nichitiu, F., Nowlan, C., Rinsland, C. P., Rochon, Y. J., Rowlands, N., Semeniuk, K., Simon, P., Skelton, R., Sloan, J. J., Soucy, M. A., Strong, K., Tremblay, P., Turnbull, D., Walker, K. A., Walkty, I., Wardle, D. A., Wehrle, V., Zander, R., and Zou, J.: Atmospheric Chemistry Experiment (ACE): Mission overview, Geophys. Res. Lett., 32, L15S01, doi: 10.1029/2005GL022386, 2005.

Bertaux, J., Kyrölä, E., and Wehr, T.: Stellar occultation technique for atmospheric ozone monitoring: GOMOS on Envisat, Earth Obs. Quart., 17-20, 2000.

Bertaux, J. L., Megie, G., Widemann, T., Chassefière, E., Pellinen, R., Kyrölä, E., Korpela, S., and Simon, P.: Monitoring of ozone trend by stellar occultations: The GOMOS instrument, Adv. Space Res., 11, 3237-3242, 1991.

Bertaux, J.-L., Kyrölä, E., Fussen, D., Hauchecorne, A., Dalaudier, F., Sofieva, V., Tamminen, J., Vanhellemont, F., Fanton d'Andon, O., Barrot, G., Mangin, A., Blanot, L., Lebrun, J. C., Fehr, T., Saavedra, L., and Fraisse, R.: Global Ozone Monitoring by Occultation of Stars: Global ozone monitoring by occultation of stars: an overview of GOMOS measurements on ENVISAT, Atmos. Chem. Phys. Discuss., 10, 9917-10076, doi:10.5194/acpd10-9917-2010, 2010.

Carn, S. A., Krotkov, N. A., Yang, K., Hoff, R. M., Prata, A. J., Krueger, A. J., Loughlin, S. C., and Levelt, P. F.: Extended observations of volcanic $\mathrm{SO} 2$ and sulfate aerosol in the stratosphere, Atmos. Chem. Phys. Discuss., 7, 2857-2871, doi:10.5194/acpd7-2857-2007, 2007.
Chin, M. and Davis, D. D.: A reanalysis of carbonyl sulfide as a source of stratospheric background sulfur aerosol, J. Geophys. Res., 100, 8993-9005, 1995.

Chu, W., McCormick, M., Lenoble, J., Brogniez, C., and Pruvost, P.: SAGE II inversion algorithm, J. Geophys. Res., 94, 83398351, 1989.

Crutzen, P.: The possible importance of OCS for the sulfate layer of the stratosphere, Geophys. Res. Lett., 3, 73-76, 1976.

Deshler, T., Hervig, M. E., Hofmann, D. J., Rosen, J. M., and Liley, J. B.: Thirty years of in situ stratospheric aerosol size distribution measurements from Laramie, Wyoming (41N), using balloon-borne instruments, J. Geophys. Res., 108, doi:10.1029/ 2002JD002514, 2003.

Deshler, T., Anderson-Sprecher, R., Jäger, H., Barnes, J., Hofmann, D. J., Clemesha, B., Simonich, D., Osborn, M., Grainger, R. G., and Godin-Beeckmann, S.: Trends in the nonvolcanic component of stratospheric aerosol over the period 1971-2004, J. Geophys. Res., 111, D01201, doi:10.1029/2005JD006089, 2006.

Hofmann, D., Barnes, J., O’Neill, M., Trudeau, M., and Neely, R.: Increase in background stratospheric aerosol observed with lidar at Mauna Loa Observatory and Boulder, Colorado, Geophys. Res. Lett., 36, L15808, doi:10.1029/2009GL039008, 2009.

Jensen, E. J., Toon, O. B., Selkirk, H. B., Spinhirne, J. D., and Schoeberl, M. R.: On the formation and persistence of subvisible cirrus clouds near the tropical tropopause, J. Geophys. Res., 101, 21361-21375, 1996.

Junge, C., Chagnon, C., and Manson, J.: Stratospheric aerosols, J. Meteorol., 18, 80-108, 1961.

Kamei, A., Sugimoto, N., Matsui, I., Shimizu, A., and Shibata, T.: Volcanic aerosol layer observed by shipboard lidar over the tropical western Pacific, Sci. Online Lett. Atmos., 2, 001-004, doi: 10.2151/sola.2006-001, 2006.

Kyrölä, E., Tamminen, J., Leppelmeier, G., Sofieva, V., Hassinen, S., Bertaux, J., Hauchecorne, A., Dalaudier, F., Cot, C., Korablev, O., Fanton d'Andon, O., Barrot, G., Mangin, A., Theodore, B., Guirlet, M., Etanchaud, F., Snoeij, P., Koopman, R., Saavedra, L., Fraisse, R., Fussen, D., and Vanhellemont, F.: GOMOS on Envisat - an overview, Adv. Space Res., 33, 10201028, 2004.

Kyrölä, E., Tamminen, J., Sofieva, V., Bertaux, J.-L., Hauchecorne, A., Dalaudier, F., Fussen, D., Vanhellemont, F., Fanton d'Andon, O., Barrot, G., Guirlet, M., Mangin, A., Blanot, L., Fehr, T., Saavedra de Miguel, L., and Fraisse, R.: Retrieval of atmospheric parameters from GOMOS data, Atmos. Chem. Phys. Discuss., 10, 10145-10217, doi:10.5194/acpd-10-10145-2010, 2010.

Leung, F.-Y. T., Colussi, A. J., Hoffmann, M. R., and Toon, G. C.: Isotopic fractionation of carbonyl sulfide in the atmosphere: Implications for the source of background stratospheric sulfate aerosol, Geophys. Res. Lett., 29(10), 1474, doi:10.1029/2001GL013955, 2002.

Lucke, R. L., Korwan, D. R., Bevilacqua, R., Hornstein, J. S., Shettle, E. P., Chen, D. T., Daehler, M., Lumpe, J. D., Fromm, M. D., Debrestian, D., Neff, B., Squire, M., König-Langlo, G., and Davies, J.: The Polar Ozone and Aerosol Measurement (POAM) III instrument and early validation results, J. Geophys. Res., 104, 18785-18799, 1999.

Poole, L. R. and McCormick, M. P.: Airborne lidar observations of Arctic polar stratospheric clouds: Indications of two distinct growth stages, Geophys. Res. Lett., 15, 21-23, 1988. 
Poole, L. R., Trepte, C. R., Harvey, V. L., Toon, G. C., and Van Valkenburg, R. L.: SAGE III observations of Arctic polar stratospheric clouds - December 2002, Geophys. Res. Lett., 30(23), 2216, doi:10.1029/2003GL018496, 2003.

Prata, A. J., Carn, S. A., Stohl, A., and Kerkmann, J.: Long range transport and fate of a stratospheric volcanic cloud from Soufrière Hills volcano, Montserrat, Atmos. Chem. Phys., 7, 5093-5103, doi:10.5194/acp-7-5093-2007, 2007.

Robock, A.: Volcanic eruptions and climate, Rev. Geophys., 38, 191-219, 2000.

Rodgers, C.: Inverse Methods for Atmospheric Sounding - Theory and Practice, World Scientific, first edn., 108-110, 2000.

Smithsonian Institution: Bulletin of the Global Volcanism Network, 30(2): February 2005, Manam, http://www.volcano.si.edu/ reports/bulletin, 2005.

Sofieva, V. F., Kan, V., Dalaudier, F., Kyrola, E., Tamminen, J., Bertaux, J.-L., Hauchecorne, A., Fussen, D., and Vanhellemont, F.: Influence of scintillation on quality of ozone monitoring by GOMOS, Atmos. Chem. Phys., 9, 9197-9207, doi:10.5194/acp9-9197-2009, 2009.

Solomon, S., Borrmann, S., Garcia, R. R., Portmann, R., Thomason, L., Poole, L. R., Winker, D., and McCormick, M. P.: Heterogeneous chlorine chemistry in the tropopause region, J. Geophys. Res., 102, 21411-21429, 1997.

SPARC: Report no. 4: Assessment of Stratospheric Aerosol Properties (ASAP) - edited by: Thomason, L. and Peter, Th., Report WCRP-124/WMO/TD-No. 1295, WMO/ICSU/IOC World Climate Research Programme, 2006.

Strawa, A. W., Drdla, K., Fromm, M., Pueschel, R. F., Hoppel, K. W., Browell, E. V., Hamill, P., and Dempsey, D. P.: Discriminating Types Ia and Ib polar stratospheric clouds in POAM satellite data, J. Geophys. Res., 107, doi:10.1029/2001JD000458, 2002.

Tamminen, J., Kyrölä, E., Sofieva, V. F., Laine, M., Bertaux, J.-L., Hauchecorne, A., Dalaudier, F., Fussen, D., Vanhellemont, F., Fanton d'Andon, O., Barrot, G., Mangin, A., Guirlet, M., Blanot, L., Fehr, T., Saavedra de Miguel, L., and Fraisse, R.: GOMOS data characterization and error estimation, Atmos. Chem. Phys. Discuss., 10, 6755-6796, doi:10.5194/acpd10-6755-2010, 2010.

Thomason, L., Pitts, M. C., and Winker, D. M.: CALIPSO observations of stratospheric aerosols: a preliminary assessment, Atmos. Chem. Phys., 7, 5283-5290, doi:10.5194/acp-7-5283-2007, 2007.
Thomason, L. W. and Taha, G.: SAGE III aerosol extinction measurements: Initial results, Geophys. Res. Lett., 30(12), 1631, doi: 10.1029/2003GL017317, 2003.

Twomey, S.: Introduction to the Mathematics of Inversion in Remote Sensing and Indirect Measurements, Elsevier Scientific Publishing Company, New York, USA, 122-127, 1985.

Vanhellemont, F., Fussen, D., Bingen, C., Kyrölä, E., Tamminen, J., Sofieva, V., Hassinen, S., Verronen, P., Seppala, A., Bertaux, J.L., Hauchecorne, A., Dalaudier, F., Fanton d'Andon, O., Barrot, G., Mangin, A., Theodore, B., Guirlet, M., Renard, J.-B., Fraisse, R., Snoeij, P., Koopman, R., and Saavedra, L.: A 2003 stratospheric aerosol extinction and PSC climatology from GOMOS measurements on Envisat, Atmos. Chem. Phys., 5, 2413-2417, doi:10.5194/acp-5-2413-2005, 2005.

Vanhellemont, F., Fussen, D., Dodion, J., Bingen, C., and Mateshvili, N.: Choosing a suitable analytical model for aerosol extinction spectra in the retrieval of UV/visible satellite occultation measurements, J. Geophys. Res., 111, D23203, doi: 10.1029/2005JD006941, 2006.

Vanhellemont, F., Tétard, C., Bourassa, A., Fromm, M., Dodion, J., Fussen, D., Brogniez, C., Degenstein, D., Gilbert, K. L., Turnbull, D. N., Bernath, P., Boone, C., and Walker, K. A.: Aerosol extinction profiles at $525 \mathrm{~nm}$ and $1020 \mathrm{~nm}$ derived from ACE imager data: comparisons with GOMOS, SAGE II, SAGE III, POAM III, and OSIRIS, Atmos. Chem. Phys., 8, 2027-2037, doi:10.5194/acp-8-2027-2008, 2008.

Vernier, J. P., Pommereau, J. P., Garnier, A., Pelon, J., Larsen, N., Nielsen, J., Christensen, T., Cairo, F., Thomason, L. W., Leblanc, T., and McDermid, I. S.: Tropical stratospheric aerosol layer from CALIPSO lidar observations, J. Geophys. Res., 114, D00H10, doi:10.1029/2009JD011946, 2009.

Wang, P., Minnis, P., McCormick, M., Kent, G., and Skeens, K.: A 6-year climatology of cloud occurrence frequency from Stratospheric Aerosol and Gas Experiment II observations (19851990), J. Geophys. Res., 101, 29407-29429, 1996.

Zondlo, M. A., Hudson, P. K., Prenni, A. J., and Tolbert, M. A.: Chemistry and microphysics of Polar Stratospheric Clouds and Cirrus Clouds, Ann. Rev. Phys. Chem., 51, 473-499, doi:10. 1146/annurev.physchem.51.1.473, 2000. 